\title{
Genetic characterization of the scyphozoan jellyfish Aurelia spp. in Chinese coastal waters using mitochondrial markers
}

\author{
Zhijun Dong a, ${ }^{\text {, }}$ Zhongyuan Liu ${ }^{\text {a, b}}$, Dongyan Liu ${ }^{a}$ \\ ${ }^{a}$ Key Laboratory of Coastal Zone Environmental Processes and Ecological Remediation, Yantai Institute of Coastal Zone Research, \\ Chinese Academy of Sciences, Yantai, Shandong 264003, PR China \\ ${ }^{\mathrm{b}}$ University of the Chinese Academy of Sciences, Beijing 100049, PR China
}

\section{A R T I C L E I N F O}

\section{Article history:}

Received 27 November 2014

Accepted 28 February 2015

Available online 24 March 2015

\section{Keywords:}

Aurelia sp.1

Mitochondrial DNA

Genetic differentiation

Genetic diversity

Bohai Sea

Yellow Sea

Jellyfish blooms

\begin{abstract}
A B S T R A C T
Blooms of the moon jellyfish Aurelia spp. have occurred in the harbors and coastal waters around the world. The phylogenetic relationship and genetic characterization of Aurelia spp. was determined along the Chinese coastal waters based on sequences of the mitochondrial cytochrome c oxidase subunit I (COI) gene. The molecular analysis confirmed that all samples collected in Chinese coastal waters were Aurelia sp.1. We also analyzed the phylogenetic and population genetic structure of Aurelia sp.1 using the newly generated sequences supplemented with existing data from previous studies. The phylogenetic analyses of the COI regions did not support geographically restricted groups among the global samples of Aurelia sp.1. Analysis of molecular variance (AMOVA) indicated a complex genetic population structure and pattern of connectivity. Populations of Aurelia sp.1 were highly structured between most sampling sites over distances as small as $100 \mathrm{~km}$ (Rizhao and Qingdao) in certain cases. However, non-significant pairwise $F_{\mathrm{ST}}$ values were also observed between short geographic distances (Yantai, Rongcheng and Qingdao) and relatively distant sampling sites (Caofeidian, Rizhao and Japan). The life-cycle characteristics, together with the prevailing ocean currents in this region and possible anthropogenic introduction, were proposed and discussed as the main factors that determined the genetic patterns of Aurelia sp.1.
\end{abstract}

() 2015 Elsevier Ltd. All rights reserved.

\section{Introduction}

The moon jellyfish Aurelia spp. (Cnidaria: Scyphozoa) is distributed worldwide in coastal and shelf sea marine environments between $70^{\circ} \mathrm{N}$ and $40^{\circ} \mathrm{S}$ (Lucas, 2001). Historically, 12 Aurelia species have been described based on morphological variability in the medusa (Mayer, 1910; Kramp, 1961). However, only Aurelia aurita and Aurelia limbata are recognized as distinct species (Russell, 1970). Recently, phylogenetic analysis of the genus Aurelia revealed 13 cryptic species that appear to be regionally restricted (Dawson and Jacobs, 2001; Schroth et al., 2002; Dawson, 2005; Ki et al., 2008). For example, Aurelia labiata was recognized as native to Pacific North America (Canada and USA) (Wrobel and Mills, 1998), while Aurelia sp.2 was distributed in marine environments in Brazil, Aurelia sp.3 in Palau, Aurelia sp.4 in Indonesia, Palau and Hawaii, Aurelia sp.5 in Croatia, Aurelia sp.7 in New Zealand and Tasmania, Aurelia sp.9 in the Gulf of Mexico, and Aurelia

\footnotetext{
* Corresponding author. Tel./fax: +86 5352109270.

E-mail address: zjdong@yic.ac.cn (Z. Dong).
} 
sp.10 in Alaska (Dawson and Jacobs, 2001; Schroth et al., 2002; Dawson, 2003, 2005; Crawford et al., 2011; Ramšak et al., 2012).

Due to intensive human activity, many marine species are introduced to seawaters beyond their natural geographic range either unintentionally or intentionally. Several cryptic species of Aurelia spp. have disjunct distributions thought to be due to the anthropogenic introduction of exotic species (Kideys and Gucu, 1995; Coles et al., 1999; Dawson, 2005). For example, the distribution of Aurelia sp.4 in the western Pacific and Pearl Harbor was thought to be based on introductions dating to the Second World War (Coles et al., 1999), while Aurelia sp.8 occurred with a Lessepsian distribution in the Adriatic, Mediterranean and Red Seas due to the opening of the Suez Canal (Kideys and Gucu, 1995). Aurelia sp.1 was found to be distributed in major warm-temperate regions around the globe, including Australia, California, France, Japan and Korea (Dawson and Jacobs, 2001; Schroth et al., 2002; Dawson, 2005; Ki et al., 2008).

Jellyfish invasions are not easily distinguished due to species crypsis and morphological plasticity in new abiotic or trophic environments (Graham and Bayha, 2007). However, molecular genetics approaches are useful for distinguishing invading cryptic species with morphological plasticity. The cytochrome c oxidase subunit I (COI) gene is one of the most frequently used mitochondrial genes for genetic analysis because it is easily amplified using the polymerase chain reaction method and conserved primers (Folmer et al., 1994). Additionally, intra- and inter specific variations of the Medusozoan mtDNA COI gene make it an appropriate choice for use as a DNA barcode for species-level identification (Holland et al., 2004; Folino-Rorem et al., 2009; Ortman et al., 2010; Laakmann and Holst, 2014). For example, the C. andromeda invasion of the Hawaiian Islands was identified by examining the global molecular phylogeny of Cassiopea spp. based on the mtDNA COI gene (Holland et al., 2004). Furthermore, multiple cryptic species in the genus Cordylophora were revealed as invasive species based on molecular analysis of mtDNA COI, 16S rRNA and 28S rRNA sequences (Folino-Rorem et al., 2009).

In Chinese seas, the aggregation and blooms of Aurelia spp. have mainly been observed in harbors and inshore areas in temperate regions, including the Yellow Sea and Bohai Sea (Dong et al., 2010; Wan and Zhang, 2012; Dong et al., 2014; Wang and Sun, 2015). In a previous study, Aurelia spp. collected in the East Margin Sea (i.e., Japan and Korea) were identified to be a single species (Aurelia sp.1)(Dawson, 2005; Ki et al., 2008). However, the taxonomy and genetic connectivity of Aurelia spp. in Chinese coastal waters were not well resolved. In this study, we collected individuals of Aurelia spp. from six different sites close to the harbor in northern Chinese coastal waters. The aim of our study was to investigate the existence of cryptic species in the genus Aurelia in Chinese coastal waters. Finally, the phylogeographic patterns of this species were also revealed using the mtDNA COI gene.

\section{Materials and methods}

\subsection{Sample collection}

A total of 103 individuals of Aurelia spp. were collected in six geographic locations in the Bohai Sea and Yellow Sea during the local jellyfish blooming periods (between July and September) in 2013 and 2014 (Fig. 1; Table S1): (I) the Bohai Sea region (BH) including locations near Caofeidian (CFD) and Weifang (WF); (II) the Northern Yellow Sea region (NY) including locations near Yantai (YT) and Rongcheng (RC); and (III) the southern Yellow Sea region (SY) including locations near Qingdao (QD) and Rizhao (RZ). Medusae tissue extracted from the bell margin or gonads was preserved in $95 \%$ ethanol and then stored at $-20^{\circ} \mathrm{C}$ until DNA extraction.

\subsection{DNA extraction, PCR amplification, sequencing and alignment}

Total genomic DNA was extracted using the TIANamp Marine Animals DNA Kit (TIANGEN, Beijing, China). The mitochondrial COI fragments from Aurelia spp. were amplified using the universal primers LCO1490 (GGTCAACAAATCATAAAGATATTGG) and HCO2198 (TAAACTTCAGGGTGACCAAAAAATCA) under the PCR conditions previously described (Folmer et al., 1994). The PCR reactions were carried out in a volume of $50 \mu \mathrm{L}$ that consisted of 50-100 ng genomic DNA, $1 \times$ PCR buffer, $1.5 \mathrm{mM} \mathrm{MgCl} 2,0.2 \mathrm{mM}$ dNTPs, $0.25 \mathrm{mM}$ primers, and $2.5 \mathrm{U}$ Taq DNA polymerase (TIANGEN, China). The temperature profile was defined as follows: $94{ }^{\circ} \mathrm{C}$ for $3 \mathrm{~min} ; 30$ cycles of denaturation at $94{ }^{\circ} \mathrm{C}$ for $30 \mathrm{~s}$, annealing at $54.5^{\circ} \mathrm{C}$ for $30 \mathrm{~s}$ and extension at $72{ }^{\circ} \mathrm{C}$ for $60 \mathrm{~s}$; followed by a final extension at $72{ }^{\circ} \mathrm{C}$ for $5 \mathrm{~min}$. The PCR products were analyzed by $1.0 \%$ agarose gel electrophoresis according to a standard method.

PCR-amplified DNA fragments were purified and sequenced with an ABI 3730 automatic DNA sequencer at Sangon Biotech Co., Ltd (Shanghai, China) using the same primers described above. All PCR products were sequenced in both directions to obtain accurate sequences.

The DNA sequence fragments were verified, edited and assembled with BioEdit 7.0 (Hall, 2005). The sequences were blasted in NCBI to confirm their identities. Additionally, related Aurelia spp. sequences were obtained from GenBank for phylogenetic analyses (Table 1). The total dataset consisted of $103 \mathrm{COI}$ sequences from this study and 62 COI sequences obtained from GenBank. The alignments were conducted with MEGA 5.0 (Ballard and Melvin, 2010); the total length of the alignments was 576 bp. A. aurita (JX995329) was used as an outgroup for the phylogenetic analyses.

\subsection{Data analyses}

The nucleotide composition and variable sites were analyzed in MEGA 5.0. The genetic diversity indices of mtDNA (nucleotide diversity $[\pi]$ and haplotype diversity $[h]$ ) were calculated using DnaSP 5.0 (Librado and Rozas, 2009). 


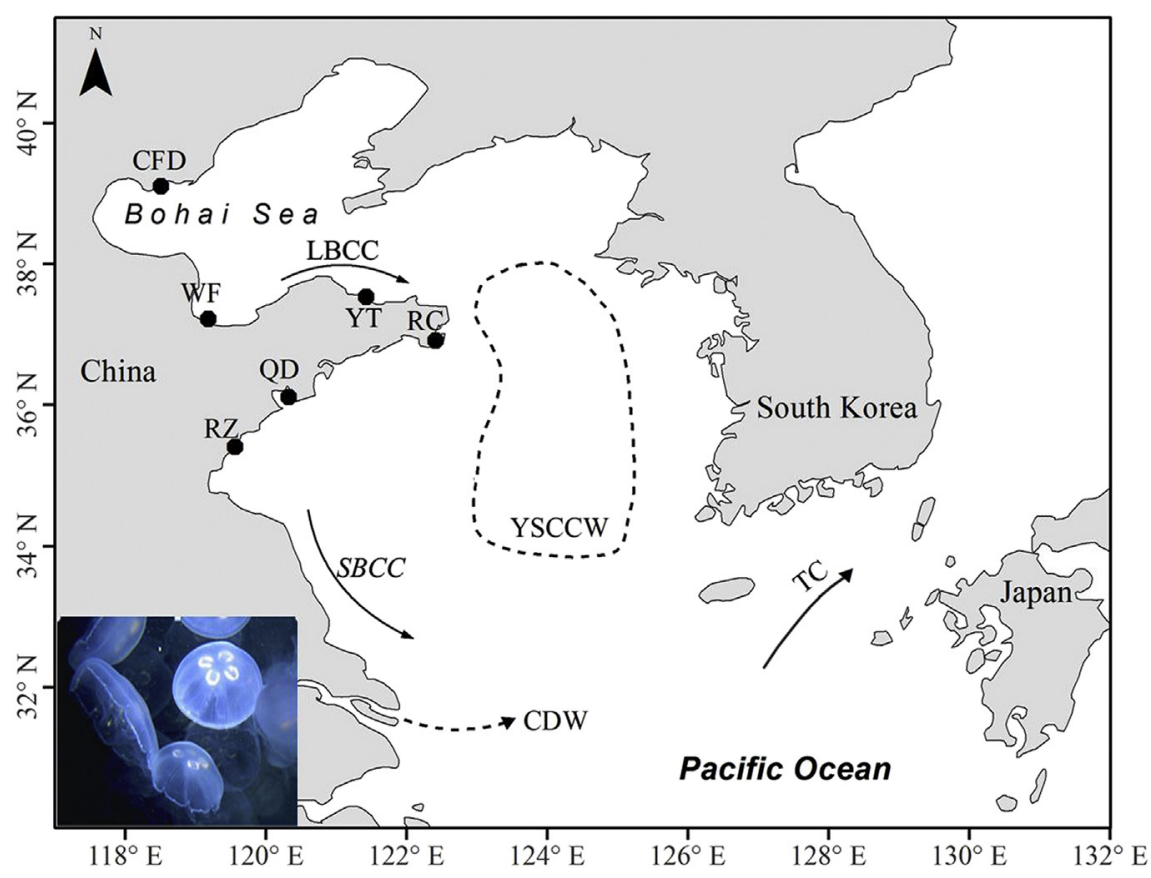

Fig. 1. Sampling sites of Aurelia spp. in Chinese coastal waters. Abbreviation IDs for geographic regions: CFD, Caofeidian; WF, Weifang; YT, Yantai; RC, Rongcheng; QD, Qingdao; RZ, Rizhao. Abbreviation IDs for currents: LBCC, Lubei Coastal Current; SBCC, Subei Coastal Current; CDW, Changjiang diluted water; YSCCW, Yellow Sea Cold Current Water; TC, Tsushima Current.

Phylogenetic analyses were conducted on two datasets (one consisted of all samples and 13 identified Aurelia species and the other consisted of all samples and Aurelia sp.1) using Bayesian methods. The best-fit model of evolution was selected by jmodeltest 2.1.4 (Darriba et al., 2012). The best suitable model under the Akaike information criterion (Akaike, 1992) was GTR + I ( I = 0.614) for the first dataset and HKY for the second dataset. Only distinct haplotypes were used for phylogenetic analyses on both datasets using MrBayes 3.2 (Ronquist and Huelsenbeck, 2003). For both datasets, two parallel Markov chain Monte Carlo (MCMC) processes were run with four chains for 2,000,000 generations and sampled every 100 generations. The first 25\% of trees were discarded as burn-in after checking the stationary using TRACER1.4.1 (Rambaut and Drummond, 2007). Phylogenetic relationships were visualized with FigTree 1.4.0 (Rivera et al., 2004). Relationships among haplotypes could be more intuitively and accurately visualized through networks. All populations of Aurelia sp. 1 were used to construct networks with Network 4.6 (http://www.fluxus-engineering.com/) using the Median-joining method under default settings (Bandelt et al., 1999).

Genetic differentiation could be qualified by pairwise $\phi_{\text {st }}$ values. The TrN model was used with 10,000 permutations (Tamura and Nei, 1993). The relative proportion of variation within and between populations was obtained through the analysis of molecular variance (AMOVA). Both values were calculated by the program Arlequin 3.5 (Excoffier and Lischer, 2010). A spatial analysis of molecular variance (SAMOVA) was performed to further test for population structure (Dupanloup et al., 2002). Monmonier's maximum difference algorithm was then used to identify putative genetic barriers to gene flow across the oceanographic landscapes (Monmonier, 1973). The correlation between geographic and genetic distances was tested by a Mantel test with 1000 permutations using the Allele in Space 1.0 software (Miller, 2005).

The past demographic expansions were detected by the neutrality statistics Fu's Fs (Fu, 1997) and Ramos-Onsins and Rozas's $R_{2}$ (Ramos-Onsins and Rozas, 2002). Fu's Fs and $R_{2}$ have been suggested as the most powerful tests for detecting sudden population growth or contractions. All the neutrality statistics were calculated using DnaSP 5.0.

\section{Results}

\subsection{Genetic variability}

A total of 103 COI sequences revealed 19 haplotypes defined by 12 polymorphic sites, of which 8 were parsimony informative sites. The haplotype diversity $(h)$ and nucleotide diversity $(\pi)$ were calculated across geographic regions (Table 2 ). Overall nucleotide diversity in Aurelia sp. 1 was $\pi=0.0041$, while the corresponding haplotype diversity was $h=0.66$. Across all samples, $\pi=0.0034-0.0046$ and $h=0.44-0.71$. The highest haplotype diversity was calculated in YT (0.713) and the lowest in RZ (0.436). The highest nucleotide diversity was calculated in RC (0.458) and the lowest in RZ (0.340). 
Table 1

Related sequences from GenBank.

\begin{tabular}{|c|c|c|}
\hline Species & Isolation locality & GenBank number \\
\hline Aurelia aurita & Turkey: Bosporus & KC789082 \\
\hline Aurelia labiata & USA: Tomales Bay, California & AY903077 \\
\hline Aurelia limbata & Japan: Hokkaido & AY903189 \\
\hline Aurelia sp.1 & USA: Marina del Rey, Los Angeles, California & AY903078 \\
\hline Aurelia sp.1 & USA: Marina del Rey, Los Angeles, California & AY903079 \\
\hline Aurelia sp.1 & USA: Marina del Rey, Los Angeles, California & AY903080 \\
\hline Aurelia sp.1 & USA: Marina del Rey, Los Angeles, California & AY903081 \\
\hline Aurelia sp.1 & USA: Long Beach, Los Angeles, California & AY903083 \\
\hline Aurelia sp.1 & USA: Long Beach, Los Angeles, California & AY903084 \\
\hline Aurelia sp.1 & USA: Long Beach, Los Angeles, California & AY903085 \\
\hline Aurelia sp.1 & USA: Newport Beach, Los Angeles, California & AY903086 \\
\hline Aurelia sp.1 & USA: Newport Beach, Los Angeles, California & AY903087 \\
\hline Aurelia sp.1 & USA: Newport Beach, Los Angeles, California & AY903088 \\
\hline Aurelia sp.1 & USA: Newport Beach, Los Angeles, California & AY903185 \\
\hline Aurelia sp.1 & USA: San Diego, Los Angeles, California & AY903090 \\
\hline Aurelia sp.1 & USA: San Diego, Los Angeles, California & AY903091 \\
\hline Aurelia sp.1 & USA: San Diego, Los Angeles, California & AY903092 \\
\hline Aurelia sp.1 & Australia: Mooloolaba Harbour, Queensland & AY903167 \\
\hline Aurelia sp.1 & Australia: Mooloolaba Harbour, Queensland & AY903128 \\
\hline Aurelia sp.1 & Australia: Greys Point, Port Hacking, New South Wales & AY903142 \\
\hline Aurelia sp.1 & Australia: Coila Lake, New South Wales & AY903147 \\
\hline Aurelia sp.1 & Australia: Coila Lake, New South Wales & AY903148 \\
\hline Aurelia sp.1 & Australia: Coila Lake, New South Wales & AY903149 \\
\hline Aurelia sp.1 & Australia: Coila Lake, New South Wales & AY903150 \\
\hline Aurelia sp.1 & Australia: Lake Illawarra, New South Wales & AY903153 \\
\hline Aurelia sp.1 & Australia: Lake Illawarra, New South Wales & AY903154 \\
\hline Aurelia sp.1 & Australia: Tuggerah Lake, New South Wales & AY903155 \\
\hline Aurelia sp.1 & Australia: Tuggerah Lake, New South Wales & AY903157 \\
\hline Aurelia sp.1 & Australia: Tuggerah Lake, New South Wales & AY903158 \\
\hline Aurelia sp.1 & Australia: Tuggerah Lake, New South Wales & AY903159 \\
\hline Aurelia sp.1 & Australia: Tuggerah Lake, New South Wales & AY903160 \\
\hline Aurelia sp.1 & Australia: Lake Macquarie, New South Wales & AY903161 \\
\hline Aurelia sp.1 & Australia: Lake Macquarie, New South Wales & AY903162 \\
\hline Aurelia sp.1 & Australia: Lake Macquarie, New South Wales & AY903163 \\
\hline Aurelia sp.1 & Australia: Lake Macquarie, New South Wales & AY903164 \\
\hline Aurelia sp.1 & Australia: Lake Macquarie, New South Wales & AY903165 \\
\hline Aurelia sp.1 & Australia: Lake Macquarie, New South Wales & AY903166 \\
\hline Aurelia sp.1 & Australia: Darling Harbour, New South Wales & AY903143 \\
\hline Aurelia sp.1 & Australia: Millers Point, New South Wales & AY903130 \\
\hline Aurelia sp.1 & Australia: Millers Point, New South Wales & AY903131 \\
\hline Aurelia sp.1 & Australia: Port Jackson, New South Wales & AY903181 \\
\hline Aurelia sp.1 & Australia: Port Jackson, New South Wales & AY903182 \\
\hline Aurelia sp.1 & Australia: Port Jackson, New South Wales & AY903183 \\
\hline Aurelia sp.1 & Australia: Huon Estuary, Tasmania & AY903151 \\
\hline Aurelia sp.1 & Australia: Perth, Western Australia & AY903126 \\
\hline Aurelia sp.1 & Australia: Perth, Western Australia & AY903127 \\
\hline Aurelia sp.1 & Australia: Perth, Western Australia & AY903177 \\
\hline Aurelia sp.1 & Australia: Perth, Western Australia & AY903178 \\
\hline Aurelia sp.1 & Australia: Perth, Western Australia & AY903180 \\
\hline Aurelia sp.1 & Japan: Miyazu Bay, Honshu & AY903168 \\
\hline Aurelia sp.1 & Japan: Miyazu Bay, Honshu & AY903169 \\
\hline Aurelia sp.1 & Japan: Miyazu Bay, Honshu & AY903170 \\
\hline Aurelia sp.1 & Japan: Sakata Bay, Honshu & AY903186 \\
\hline Aurelia sp.1 & Japan: Sakata Bay, Honshu & AY903187 \\
\hline Aurelia sp.1 & Japan: Sakata Bay, Honshu & AY903188 \\
\hline Aurelia sp.1 & Japan: Tokyo Bay, Honshu & AY903203 \\
\hline Aurelia sp.1 & Japan: Tokyo Bay, Honshu & AY903204 \\
\hline Aurelia sp.1 & Japan: Tokyo Bay, Honshu & AY903205 \\
\hline Aurelia sp.1 & Japan: Tokyo Bay, Honshu & AY903206 \\
\hline Aurelia sp.1 & Japan: Tokyo Bay, Honshu & AY903116 \\
\hline Aurelia sp.1 & Japan: Uwa Bay, Inland Sea & AY903192 \\
\hline Aurelia sp.1 & Japan: Ondo Strait, Inland Sea & AY903196 \\
\hline Aurelia sp.1 & South Korea: coastal region of Incheon & EU010386 \\
\hline Aurelia sp.1 & South Korea: Busan & EU366143 \\
\hline Aurelia sp.1 & South Korea: Geoje-do & EU366144 \\
\hline Aurelia sp.2 & Brazil: Cananeia, Sao Paulo & AY903121 \\
\hline Aurelia sp.3 & Palau: Koror State & AY903096 \\
\hline Aurelia sp.4 & Indonesia: Kakaban Island, Berau & AY903145 \\
\hline Aurelia sp.5 & Croatia: Veliko Jezero, Mljet & AY903123 \\
\hline Aurelia sp.6 & Palau: Ngell Channel & AY903099 \\
\hline
\end{tabular}


Table 1 (continued)

\begin{tabular}{lll}
\hline Species & Isolation locality & GenBank number \\
\hline Aurelia sp.7 & Australia: Huon Estuary, Tasmania & AY903138 \\
Aurelia sp. 8 & Croatia: Bay of Ston & AY903135 \\
Aurelia sp. 9 & USA: Gulf of Mexico, Alabama & AY903172 \\
Aurelia sp.10 & USA: Kachemak Bay, Alaska & AY903067 \\
\hline
\end{tabular}

\subsection{Phylogenetic analysis}

A total of 13 distinct clades including A. limbata, Aurelia labiate, A. aurita and ten other Aurelia spp. were detected in an unrooted Bayesian tree (Fig. 2). All the samples collected in Chinese coastal waters clustered together with the specimens collected from Japanese, Korean, American and Australian waters that were identified as Aurelia sp.1 (Dawson and Jacobs, 2001; Schroth et al., 2002; Dawson, 2005; Ki et al., 2008).

A phylogenetic tree was generated using Bayesian analysis for all haplotypes based on global Aurelia sp.1 mtCOI sequences (Fig. 3). The phylogenetic analysis revealed several well supported groups. Hap 35 and eleven additional haplotypes formed a strongly supported clade (posterior support $=100 \%$ ), whereas Hap 39 and eight additional haplotypes formed a second well supported clade (posterior support $=93 \%$ ). However, there was no geographical association of haplotypes in the two well supported groups.

TCA analysis of global Aurelia sp.1 generated an eight step statistical parsimony network connecting all 39 haplotypes (Fig. 4). In total, there were nine haplotypes (Hap 2, Hap 4, Hap 6, Hap 9, Hap 24, Hap 25, Hap 26, Hap 27, and Hap 30) that shared more than one geographical region (Fig. 4): Hap 25 and Hap 26 were shared by all six Chinese populations; Hap 4 was shared by the QD, American and Australian populations; Hap 9 was shared by the CFD, Australian and Japanese populations; Hap 2 was shared by the American and Australian populations; Hap 6 was shared by the Australian and Japanese populations; Hap 24 was shared by the RC and Japanese populations; Hap 27 was shared by the CFD and WF populations; and Hap 30 was shared by the QD and RC populations.

\subsection{Population genetic differentiation}

The genetic distance calculated using the Tamura-Nei model among the 39 haplotypes ranged from 0.002 to 0.016 with an average value of 0.008. Based on the sequence distances derived using the Tajima and Nei method, the AMOVA test showed that $92.82 \%$ of the genetic variation occurred within populations $(P<0.05)$, whereas $6.59 \%$ of the genetic variation occurred among populations within regions and $0.59 \%$ occurred among regions (Table 3 ).

Table 4 shows the pattern of genetic differentiation among populations observed by mean pairwise $F_{\mathrm{ST}}$. These results indicated that the YT, RC and QD populations were significantly differentiated from the other two Chinese populations (WF and RZ) ( $F_{\mathrm{ST}}$ range: $\left.0.1698-0.2465, P<0.05\right)$. However, the Mantel test showed that no significant correlation between genetic and geographic distances was found among Chinese populations $(r=0.0053, p=0.38)$. The YT, RC and QD populations were also significantly differentiated from the Japanese population ( $F_{\mathrm{ST}}$ range: $\left.0.1585-0.1902, P<0.05\right)$. However, no significant genetic differentiation was detected among CFD, RZ, WF and the Japanese populations. All Chinese and Japanese populations were significantly differentiated from the American and Australian populations ( $F_{\mathrm{ST}}$ range: $0.2666-0.7328$, $P<0.01$ ). These results were further identified by SAMOVA analysis which recognized Chinese and Japanese populations as one group, American, Australian and Korean populations as the second group $\left(K=2, F_{\mathrm{CT}}=0.4493, p=0.011\right)$. Fu's Fs test for the entire region was statistically significant negative $(-5.352, p<0.01)$. Meanwhile, a low value of the $R_{2}$ statistics $(0.068)$ also indicated that the Aurelia sp.1 populations might have experienced population expansion.

\section{Discussion}

Recent genetic studies on moon jellyfish have reported high levels of intraspecific diversity, and at least 13 cryptic species have been revealed (Dawson and Jacobs, 2001; Schroth et al., 2002; Dawson, 2005; Ki et al., 2008). Among these species, Aurelia sp.1, Aurelia sp.4 and Aurelia sp.8 were thought to be introduced species (Dawson, 2005). In the present study, sequence analysis of 103 specimens from six localities revealed that a single cryptic species (Aurelia sp.1) was present in our collections. In previous studies, Aurelia sp.1 was also identified in Korea, Japan, California, Australia and the Mediterranean coast of France (Dawson and Jacobs, 2001; Dawson and Martin, 2001; Schroth et al., 2002; Dawson, 2005; Ki et al., 2008). The ocean model showed limited dispersion in the 1-year lifespan of medusa among Japanese, Australian and North American waters; therefore, the global distribution of Aurelia sp.1 in Australia and America is most likely due to anthropogenic translocation (Dawson, 2005). Moreover, the latitudinal range of Aurelia sp.1 distribution in these coastal regions was similar. Such a large geographic range that includes disjunct populations suggests that Aurelia sp. 1 may be an introduced species that is adapted to survive in warm-temperate seaports or adjunct seawaters (Dawson, 2005).

The genetic diversity of mtDNA COI sequences in Aurelia sp. 1 in Chinese coastal waters (China: $h=0.66 ; \pi=0.0020$; $n=103$ ) was lower than previously found in a Japanese population $(h=0.87 ; \pi=0.0063 ; n=26)$ (Dawson, 2005). Reduced genetic diversity was also reported in Australia (Australia: $h=0.66 ; \pi=0.0048 ; n=37$ ) and California (California: $h=0.53$; 
Table 2

Genetic diversity of mitochondrial COI sequences in Aurelia sp.1 according to geographic region.

\begin{tabular}{|c|c|c|c|c|}
\hline Geographic regions & Specimens (no.) & Haplotypes (no.) & Haplotype diversity $h \pm \mathrm{SE}$ & Nucleotide diversity $\pi \pm$ SE (\%) \\
\hline CFD & 26 & 7 & $0.692 \pm 0.062$ & $0.451 \pm 0.030$ \\
\hline WF & 16 & 3 & $0.542 \pm 0.098$ & $0.377 \pm 0.074$ \\
\hline YT & 17 & 7 & $0.713 \pm 0.109$ & $0.431 \pm 0.079$ \\
\hline $\mathrm{RC}$ & 18 & 8 & $0.641 \pm 0.130$ & $0.458 \pm 0.088$ \\
\hline QD & 15 & 4 & $0.543 \pm 0.133$ & $0.407 \pm 0.094$ \\
\hline $\mathrm{RZ}$ & 11 & 2 & $0.436 \pm 0.133$ & $0.340 \pm 0.104$ \\
\hline Total & 103 & 19 & $0.662 \pm 0.034$ & $0.446 \pm 0.017$ \\
\hline
\end{tabular}

$\pi=0.0020 ; n=16)$ compared to Japan. In this study, phylogenetic analysis based on global Aurelia sp.1 mtDNA COI haplotypes revealed that the Japanese haplotypes were distributed throughout the total tree (Fig. 3). These results suggested that Aurelia sp.1 might have dispersed globally from Japanese coastal waters.

A few studies have addressed the population genetic structure in scyphozoans, suggesting that both different reproductive strategies and dispersal ability may attribute to the population genetic structure (Stopar et al., 2010; Ramšak et al., 2012; Lee et al., 2013). In general, holopelagic scyphozoans with high dispersal potential showed genetic homogeny over large geographical distances (Stopar et al., 2010). In contrast, the increased genetic diversity observed for meroplanktonic scyphozoans may be closely linked to the benthic phase (Gibbons et al., 2010; Lee et al., 2013). For example, the holopelagic scyphozoan Pelagia noctiluca showed a lack of genetic structure among Mediterranean and East Atlantic populations (Stopar et al., 2010), while significant genetic structures distinguishing three populations in the meroplanktonic scyphozoan jellyfish Rhizostoma octopus were revealed in the Irish Sea and northeastern Atlantic (Lee et al., 2013). Similarly, phylogeographic analyses confirmed the separation of three Aurelia spp. in the Mediterranean Sea (Ramšak et al., 2012). However, no significant genetic differentiation was detected in Rhizostoma pulmo in the Mediterranean Sea. One possible explanation is that the dispersal ability (including dispersal with ocean currents and active swimming) might differ between R. pulmo and Aurelia spp. Horizontal directional swimming has been observed in different scyphozoans (Albert, 2011).

Complex life-history characteristics and habitat fragmentation may be important factors for these high levels of genetic differentiation in meroplanktonic scyphozoans. Schroth et al. (2002) indicated that two important life cycle traits (strobilation frequency and temperature for strobilation onset) might coincide with the genetic differentiation of Aurelia spp.

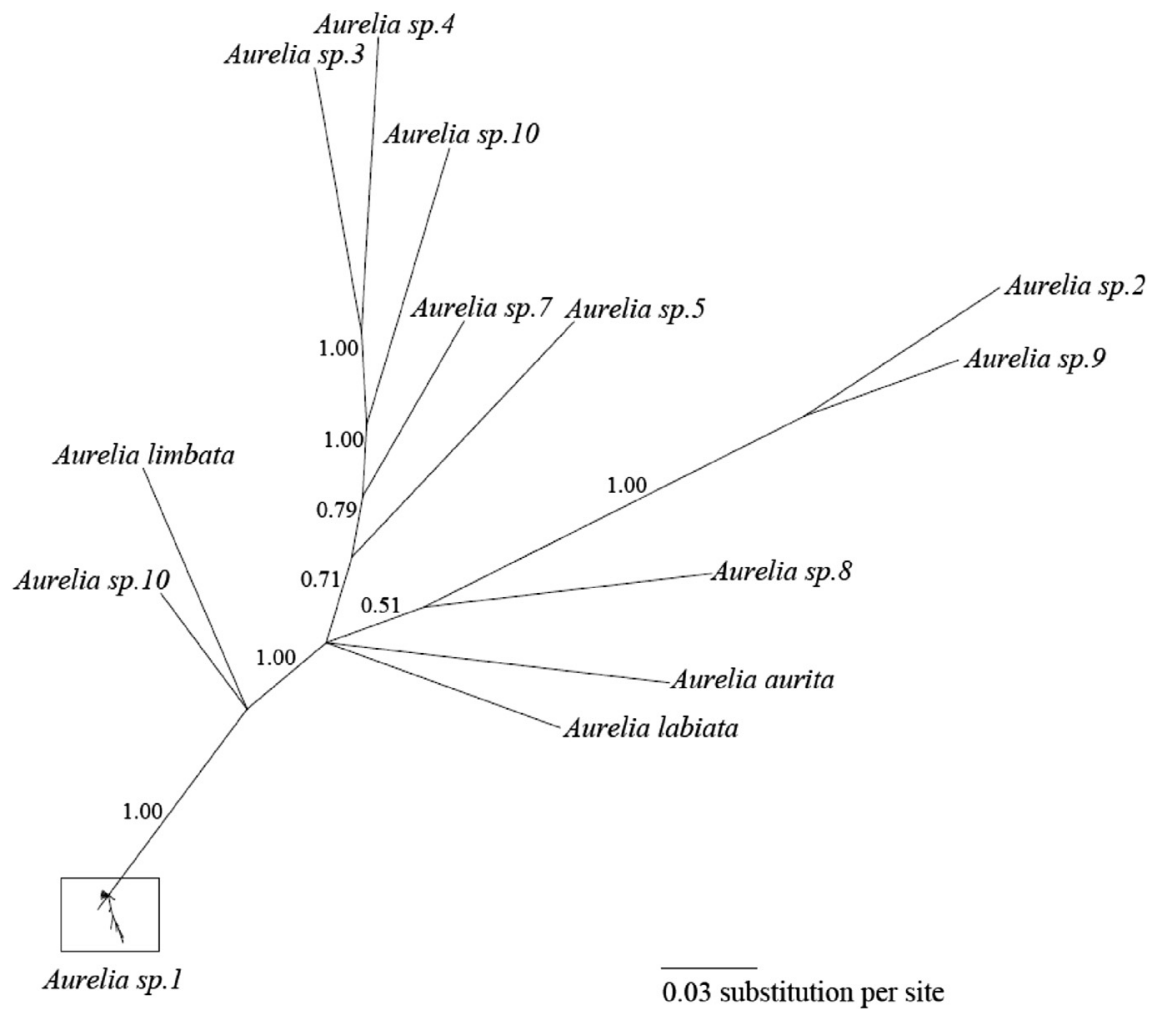

Fig. 2. Unrooted Bayesian trees showing the relationships of Aurelia sp.1. 


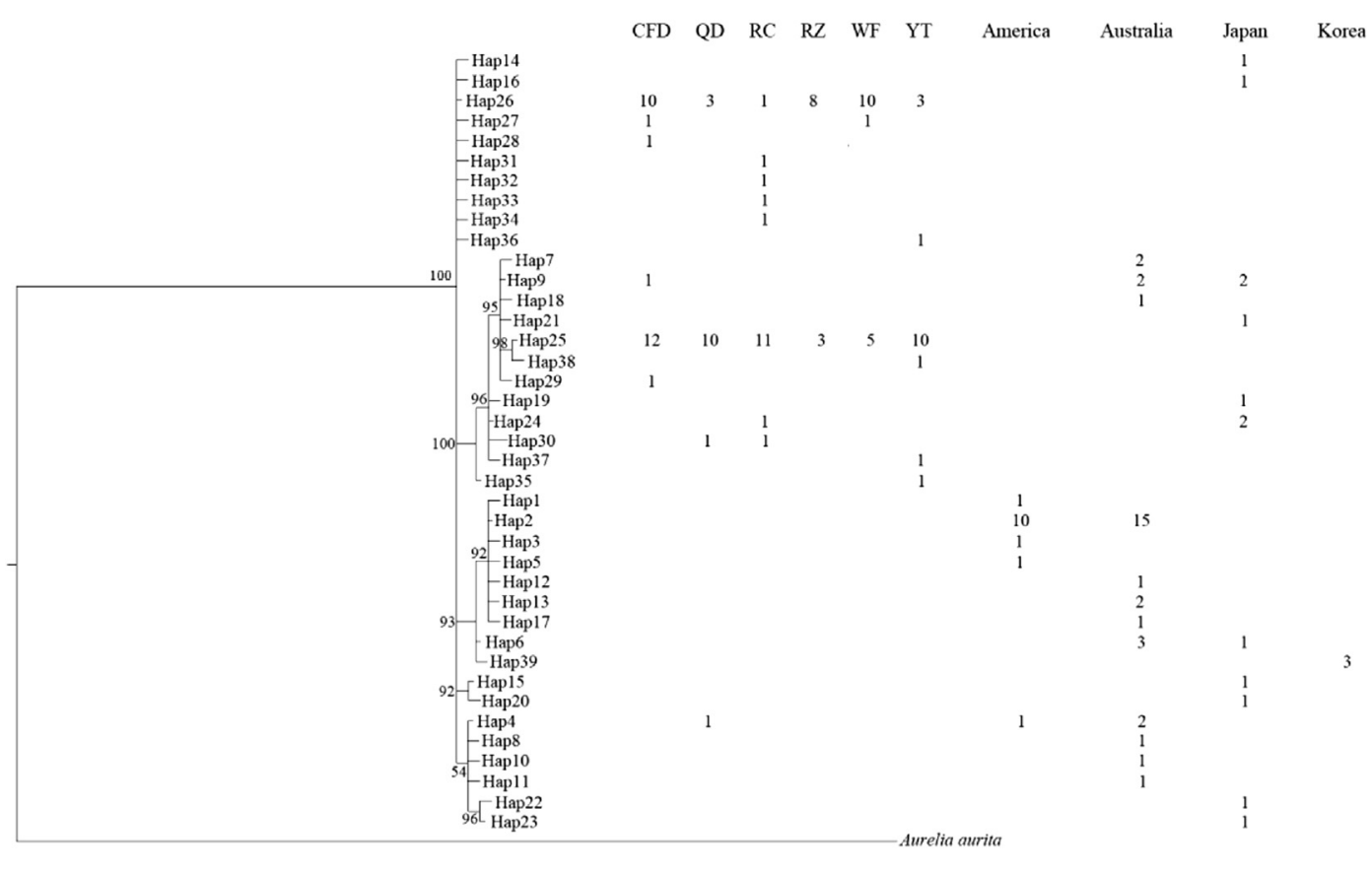

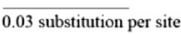

Fig. 3. Phylogenetic relationships within Aurelia sp.1 derived by Bayesian inference based on mtDNA sequences under the HKY model. Numbers at nodes indicate posterior probabilities. The distribution of haplotypes among populations is also presented.

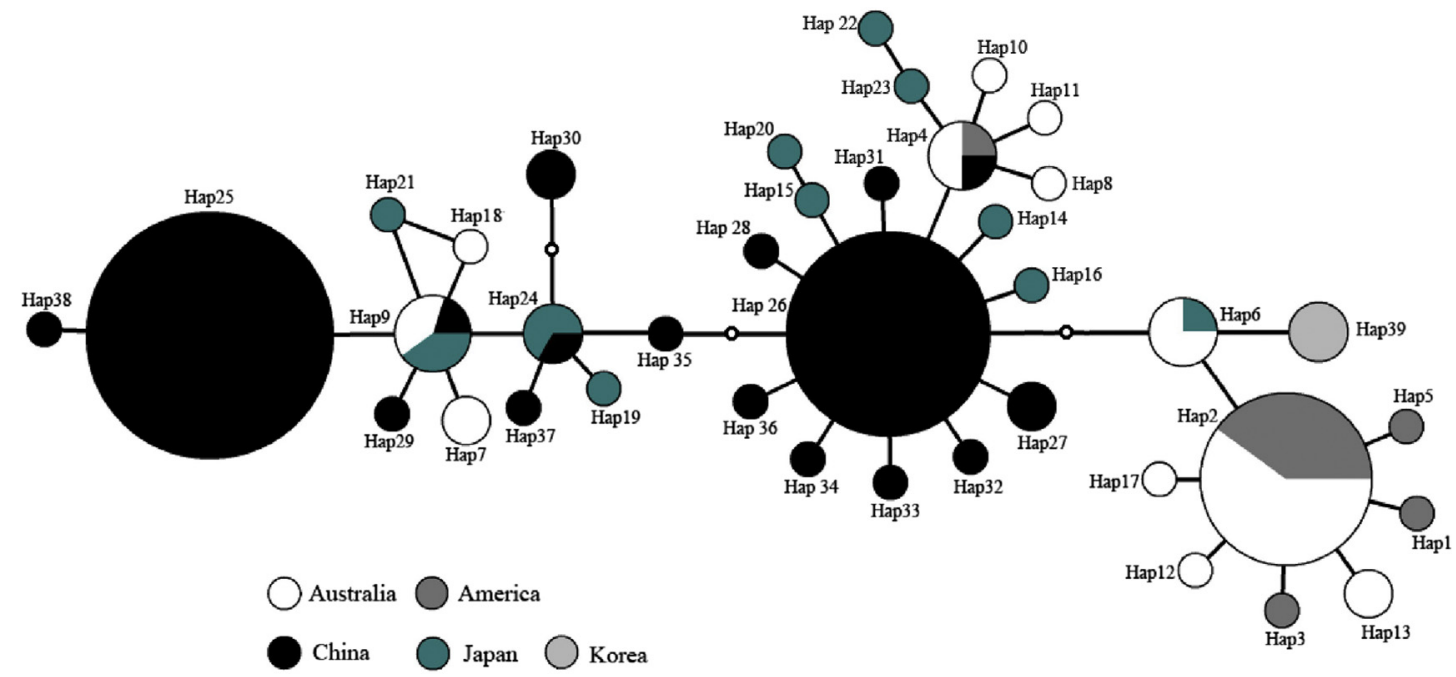

Fig. 4. Median-joining networks for all Aurelia sp.1 COI haplotypes. The color of the circle indicates the geographic region, and the size of the circle indicates the haplotype frequency. Each branch between any two shapes represents a single nucleotide substitution.

Table 3

Hierarchical analysis of molecular variance (AMOVA) of mtCOI haplotypes of Aurelia sp.1.

\begin{tabular}{|c|c|c|c|c|c|}
\hline Source of variation & d.f. & Variance component & Percentage of variation & $\varphi$ Statistic & $P$ value \\
\hline Among regions & 2 & 0.00865 & 0.59 & $\varphi_{\mathrm{CT}}=0.00592$ & 0.33376 \\
\hline Among populations within regions & 3 & 0.0963 & 6.59 & $\varphi_{\mathrm{SC}}=0.06626$ & 0.07337 \\
\hline Within populations & 97 & 1.35711 & 92.82 & $\varphi_{\mathrm{ST}}=0.07178^{*}$ & 0.02891 \\
\hline Total & 102 & 1.46206 & 100 & & \\
\hline
\end{tabular}

Structure tested: Region 1 (Caofeidian and Weifang); Region 2 (Yantai and Rongcheng); Region 3 (Qingdao and Rizhao). Asterisks indicate significant level. * $p<0.05 ;{ }^{* *} p<0.01$. 
Table 4

Fst analysis among geographical populations of Aurelia sp.1

\begin{tabular}{|c|c|c|c|c|c|c|c|c|c|}
\hline Population & America & Australia & CFD & QD & $\mathrm{RC}$ & $\mathrm{RZ}$ & WF & YT & Japan \\
\hline \multicolumn{10}{|l|}{ America } \\
\hline Australia & 0.0800 & & & & & & & & \\
\hline CFD & $0.6395^{* *}$ & $0.3962^{* *}$ & & & & & & & \\
\hline QD & $0.7328^{* *}$ & $0.4817^{* *}$ & 0.0166 & & & & & & \\
\hline $\mathrm{RC}$ & $0.6982^{* *}$ & $0.4647^{* *}$ & 0.0080 & -0.0561 & & & & & \\
\hline $\mathrm{RZ}$ & $0.6547^{* *}$ & $0.2944^{* *}$ & 0.0545 & $0.2402^{*}$ & 0.1999* & & & & \\
\hline WF & $0.6302^{* *}$ & $0.3143^{* *}$ & 0.0345 & $0.2026^{*}$ & $0.1698^{*}$ & -0.0772 & & & \\
\hline YT & $0.7325^{* *}$ & $0.4883^{* *}$ & 0.0218 & -0.0551 & -0.0439 & $0.2465^{*}$ & $0.2087^{*}$ & & \\
\hline Japan & $0.5430^{* *}$ & $0.2666^{* *}$ & 0.0753 & $0.1827^{*}$ & $0.1585^{*}$ & 0.0085 & 0.0217 & $0.1906^{*}$ & \\
\hline
\end{tabular}

Fst values are calculated from genetic divergence data among haplotypes calculated with the method of Tajima and Nei (1984). Asterisks indicate significant level. ${ }^{*} p<0.05 ;{ }^{* *} p<0.01$. Probability $P$ was calculated from 1000 replications.

populations. High pairwise $F_{S T}$ values over short geographic distances (100 km) were observed between the QD and RZ populations. These results indicate that dispersal of Aurelia sp.1 between QD and RZ is limited. Similarly, two Chlamys farreri populations (RZ and QD) were also revealed to be genetically divergent (Zhan et al., 2009). Previous study suggest that habitat fragmentation formed by marine gyres and currents is much competent for the explanation of genetic differentiation for a fine geographical scale than isolation by distance (e.g., Launey et al., 2002; Zhan et al., 2009).

However, non-significant pairwise comparisons of the $F_{\mathrm{ST}}$ values were also found over both short geographic distances (i.e., YT, RC, and QD) and large geographic distances (i.e., RZ and Japan, WF and Japan, and CFD and RZ). Previous studies indicated that the absence of isolation by distance might be caused by a recent colonization event or by long-distance dispersal (Slatkin, 1993; Palumbi, 2003). The pelagic Aurelia spp. (ephyrae and adult medusa) occurred from April to October (Dong et al., 2012; Wan and Zhang, 2012). Therefore, the coastal currents in this region may play an important role in transporting planktonic medusa. In the summer, the Lubei coastal currents flow in this region (Su and Yuan, 2005) and may potentially enhance the dispersal of Aurelia sp.1 along coastal waters of the Jiaodong Peninsula (i.e., YT, RC, and QD). The pelagic medusa of Aurelia spp. are typically found in near-shore waters and shallow estuaries and rarely in deep waters, suggesting limited dispersal for this species (i.e., Dong et al., 2014). Therefore, long distance dispersal from Japan to coastal waters of the Bohai Sea and Yellow Sea might be limited. Thus, the identification of Aurelia sp.1 in RZ and WF that are genetically identical to those found in Japan is most likely due to anthropogenic translocation.

In conclusion, our results revealed that all Aurelia spp. samples collected in Chinese coastal waters were charactered as a single cryptic species (Aurelia sp.1), authough 13 cryptic species of Aurelia spp. have been revealed in the previous study. We also demonstrated a complex genetic population structure of Aurelia sp.1 in Chinese coastal waters. The phylogeographic patterns of Aurelia sp. 1 in Chinese coastal waters were in relation to habitat fragmentation separated by marine gyres and currents, complex life-history characteristics of Aurelia sp.1, and possible anthropogenic introduction.

\section{Acknowledgments}

The authors thank Youfang Sun and Qianwen Qu for their assistance in the field investigation and experiment. This work was supported by grants from the National Natural Science Foundation of China (No.41206086), the Strategic Priority Research Program of Chinese Academy of Sciences (No.XDA05130703 and No.XDA11020405), and the Research Encouragement Foundation of Excellent Midlife-Youth Scientists of Shandong Province (No.BS2011HZ023).

\section{Appendix A. Supplementary data}

Supplementary data related to this article can be found at http://dx.doi.org/10.1016/j.bse.2015.02.018.

\section{References}

Akaike, H., 1992. Information theory as an extension of the maximum-likelihood principle. In: Petrov, B.N., Csaki, F. (Eds.), Second International Symposium on Information Theory. Akademiai Kiado, Budapest, pp. 267-281.

Albert, D.J., 2011. What's on the mind of a jellyfish? A review of behavioural observations on Aurelia sp. jellyfish. Neurosci. Biobehav. Rev. 35, 474-482.

Ballard, J.W.O., Melvin, R.G., 2010. Linking the mitochondrial genotype to the organismal phenotype. Mol. Ecol. 19, $1523-1539$.

Bandelt, H.J., Forster, P., Röhl, A., 1999. Median-joining networks for inferring intraspecific phylogenies. Mol. Bio. Evol. 16, $37-48$.

Coles, S.L., DeFelice, R.C.L., Eldredge, G., Carlton, J.T., 1999. Historical and recent introductions to non-indigenous marine species into Pearl Harbor, O'ahu, Hawaiian Islands. Mar. Biol. 135, 1247-1258.

Crawford, C.M., Moltschaniwskyj, N.A., Willcox, S., 2011. Size and characteristics of aggregations of moon jellyfish (Aurelia sp.) in Tasmania, Australia. In: Papers and Proceedings of the Royal Society of Tasmania, 145, pp. 9-15.

Darriba, D., Taboada, G.L., Doallo, R., Posada, D., 2012. jModelTest 2: more models, new heuristics and parallel computing. Nat. Methods 9, 772.

Dawson, M.N., 2003. Macro-morphological variation among cryptic species of the moon jellyfish, Aurelia (Cnidaria: Scyphozoa). Mar. Biol. 143, 369-379.

Dawson, M.N., 2005. Cyanea capillata is not a cosmopolitan jellyfish: morphological and molecular evidence for C. annaskala and C. rosea (Scyphozoa: Semaeostomeae: Cyaneidae) in south-eastern Australia. Invertebr. Syst. 19, 361-370.

Dawson, M.N., Martin, L.E., 2001. Geographic variation and ecological adaptation in Aurelia (Scyphozoa, Semaeostomeae): some implications from molecular phylogenetics. Hydrobiologia 451, 259-273. 
Dawson, M.N., Jacobs, D.K., 2001. Molecular evidence for cryptic species of Aurelia aurita (Cnidaria, Scyphozoa). Biol. Bull. $200,92-96$.

Dong, Z., Liu, D., Wang, Y., Di, B., Song, X., Shi, Y., 2012. A report on moon jellyfish Aurelia aurita bloom in Sishili bay, northern Yellow Sea of China in 2009. Aquat. Ecosyst. Health 15, 161-167.

Dong, Z., Liu, D., Keesing, J.K., 2010. Jellyfish blooms in China: dominant species, causes and consequences. Mar. Pollut. Bull. 60, 954-963.

Dong, Z., Liu, D., Keesing, J.K., 2014. Contrasting trends in populations of Rhopilema esculentum and Aurelia aurita in Chinese waters. In: Pitt, Kylie, Lucas, Cathy (Eds.), Jellyfish Blooms. Springer-Verlag, Berlin, pp. 207-218.

Dupanloup, I., Schneider, S., Excoffier, L., 2002. A simulated annealing approach to define the genetic structure of populations. Mol. Ecol. 11, $2571-2581$.

Excoffier, L., Lischer, H.E., 2010. Arlequin suite ver 3.5: a new series of programs to perform population genetics analyses under Linux and Windows. Mol. Ecol. Resour. 10, 564-567.

Folino-Rorem, N.C., Darling, J.A., D'Ausilio, C.A., 2009. Genetic analysis reveals multiple cryptic invasive species of the hydrozoan genus Cordylophora. Biol. Invasions 11, 1869-1882.

Folmer, O., Black, M., Hoeh, W., Lutz, R., Vrijenhoek, R., 1994. DNA primers for amplification of mitochondrial cytochrome c oxidase subunit I from diverse metazoan invertebrates. Mol. Mar. Biol. Biotech. 3, 294-299.

Fu, Y.X., 1997. Statistical tests of neutrality of mutations against population growth, hitchhiking and background selection. Genetics 147, 915-925.

Gibbons, M.J., Janson, L.A., Ismail, A., Samaai, T., 2010. Life cycle strategy, species richness and distribution in marine Hydrozoa (Cnidaria:Medusozoa). J. Biogeogr. 37, 441-448.

Graham, W.M., Bayha, K.M., 2007. Biological invasions by marine jellyfish. In: Nentwig, W. (Ed.), Biological Invasions. Ecol. Stud. 193, 239-255. SpringerVerlag Berlin Heidelberg.

Hall, T., 2005. Bioedit 7.0.5. Department of Microbiology, North Carolina State University.

Holland, B.S., Dawson, M.N., Crow, G.L., Hofmann, D.K., 2004. Global phylogeny of Cassiopea (Scyphozoa: Rhizostomeae): molecular evidence for cryptic species and multiple invasions of the Hawaiian Islands. Mar. Biol. 145, 1119-1128.

Ki, J.S., Hwang, D.S., Shin, K., Yoon, W.D., Lim, D., Kang, Y.S., Lee, Y., Lee, J.S., 2008. Recent moon jelly (Aurelia sp. 1) blooms in Korean coastal waters suggest global expansion: examples inferred from mitochondrial COI and nuclear ITS-5.8 S rDNA sequences. ICES J. Mar. Sci. 65, $443-452$.

Kideys, A.E., Gucu, A.C., 1995. Rhopilema nomadica: a Lessepsian scyphomedusan new to the Mediterranean coast of Turkey. Isr. J. Zool. 41, 615-617.

Kramp, P.L., 1961. Synopsis of the medusae of the world. J. Mar. Biol. Assess. U.K. 40, 1-469.

Laakmann, S., Holst, S., 2014. Emphasizing the diversity of North Sea hydromedusae by combined morphological and molecular methods. J. Plankton Res. $36,64-76$.

Launey, S., Ledu, C., Boudry, P., Bonhomme, F., Naciri-Graven, Y., 2002. Geographic structure in the European flat oyster (Ostrea edulis L.) as revealed by microsatellite polymorphism. J. Hered. 93, 331-351.

Lee, P.L.M., Dawson, M.N., Neill, S.P., Robins, P.E., Houghton, J.D.R., Doyle, T.K., Hays, G.C., 2013. Identification of genetically and oceanographically distinct blooms of jellyfish. J. R. Soc. Interface 10, 20120920.

Librado, P., Rozas, J., 2009. DnaSP v5: a software for comprehensive analysis of DNA polymorphism data. Bioinformatics 25, $1451-1452$.

Lucas, C.H., 2001. Reproduction and life history strategies of the common jellyfish, Aurelia aurita, in relation to its ambient environment. Hydrobiologia 451, $229-246$.

Mayer, A.G., 1910. Medusae of the World. In: The Scyphomedusae, vol. 3. Carnegie Institution of Washington, Washington, DC, 711 pp.

Miller, M.P., 2005. Alleles In Space (AIS): computer software for the joint analysis of interindividual spatial and genetic information. J. Hered. 96, 722-724.

Monmonier, M.S., 1973. Maximum-difference barriers: an alternative numerical regionalization method. Geograph. Anal. 5, $245-261$.

Ortman, B.D., Bucklin, A., Pagès, F., Youngbluth, M., 2010. DNA Barcoding the Medusozoa using mtCOI. Deep-Sea Res. II 57, $2148-2156$.

Palumbi, S.R., 2003. Population genetics, demographic connectivity, and the design of marine reserves. Ecol. Appl. 13, S146-S158.

Rambaut, A., Drummond, A.J., 2007. Tracer v1.4: MCMC Trace Analyses Tool. Institute of Evolution Biology, Edinburgh. URL: http://beast bio ed ac uk/Tracer.

Ramos-Onsins, S.E., Rozas, J., 2002. Statistical properties of new neutrality tests against population growth. Mol. Biol. Evol. 19, 2092-2100.

Ramšak, A., Stopar, K., Malej, A., 2012. Comparative phylogeography of meroplanktonic species, Aurelia spp. and Rhizostoma pulmo (Cnidaria: Scyphozoa) in European Seas. Hydrobiologia 690, 69-80.

Rivera, M.A.J., Kelley, C.D., Roderick, G.K., 2004. Subtle population genetic structure in the Hawaiian grouper, Epinephelus quernus (Serranidae) as revealed by mitochondrial DNA analyses. Biol. J. Linn. Soc. 81, 449-468.

Ronquist, F., Huelsenbeck, J.P., 2003. MrBayes 3: Bayesian phylogenetic inference under mixed models. Bioinformatics 19, $1572-1574$.

Russell, F.S., 1970. The Medusae of the British Isles. II. Pelagic Scyphozoa with a Supplement to the First Volume on Hydromedusae. Cambridge University Press, London, p. 284.

Schroth, W., Jarms, G., Streit, B., Schierwater, B., 2002. Speciation and phylogeography in the cosmopolitan marine moon jelly, Aurelia sp. BMC Evol. Biol. 2, $1-10$.

Slatkin, M., 1993. Isolation by distance in equilibrium and nonequilibrium populations. Evolution 47, $264-279$.

Stopar, K., Ramšak, A., Trontelj, P., Malej, A., 2010. Lack of genetic structure in the jellyfish Pelagia noctiluca (Cnidaria: Scyphozoa: Semaeostomeae) across European seas. Mol. Phylogenet. Evol. 57, 417-428.

Su, J.L., Yuan, Y.L., 2005. Coastal Hydrology of China. Ocean Press, Beijing, China.

Tajima, F., Nei, M., 1984. Estimation of evolutionary distance between nucleotide sequences. Mol. Biol. Evol. 1, $269-285$.

Tamura, K., Nei, M., 1993. Estimation of the number of nucleotide substitutions in the control region of mitochondrial DNA in humans and chimpanzees. Mol. Biol. Evol. 10, 512-526.

Wan, A., Zhang, G., 2012. Annual occurrence of moon jellyfish Aurelia sp.1 in the Jiaozhou Bay and its impacts on zooplankton community. Ocean. Limnol. Sin. 43, 494-501 (in Chinese).

Wang, Y.T., Sun, S., 2015. Population dynamics of Aurelia sp.1 ephyrae and medusae in Jiaozhou Bay, China. Hydrobiologia. http://dx.doi.org/10.1007/s10750014-2021-3.

Wrobel, D., Mills, C., 1998. Pacific coast Pelagic Invertebrates: a Guide to the Common Gelatinous Animals. Sea Challengers and Monterey Bay Aquarium, Monterey, CA.

Zhan, A., Hu, J., Hu, X., Zhou, Z., Hui, M., Wang, S., Bao, Z., 2009. Fine-scale population genetic structure of Zhikong scallop (Chlamys farreri): do local marine currents drive geographical differentiation? Mar. Biotechnol. 11, 223-235. 